\title{
PROPOSIÇÕES PARA UM MOVIMENTO MENOR
}

\section{Proposals for a smaller movement}

\author{
Erin Manning \\ Concordia University - Montreal/Canadá
}

Tradução: André Arias

\begin{abstract}
Resumo: As proposições deste texto são orientações de um processo curatorial experimental em curso durante o ano de 2019, e que serve como o ativador da série de encontros que o SenseLab facilitará em diferentes países com o título de Movimentos Menores. Na exploração transversal do que essa série de encontros pode gerar, emerge a pergunta de como é possível dar conta da entrada do movimento menor no mundo. Um processo curatorial para a ativação de movimentos menores requer uma transformação do pressuposto de que existe um campo da arte e um campo da vida, quando o binarismo entre arte e vida é desfeito. O que importa não é se é ou não arte, mas como a experiência ou o acontecimento muda as condições da experiência. Quando a arte se torna a maneira e não o fim, os movimentos menores se tornam orientadores dos processos por vir.
\end{abstract}

Palavras-chave: Movimento menor; Gesto menor; Arte; Acontecimento; Experiência.

Abstract: The propositions of this text are orientations of an experimental curatorial process underway during 2019 , which serves as the activator of the series of meetings that SenseLab will facilitate in different countries with the title of Minor Movements. In the cross-sectional exploration of what this series of encounters can generate, the question arises of how it is possible to account for the entry of the smaller movement into the world. A curatorial process for activating smaller movements requires a transformation of the assumption that there is a field of art and a field of life when the binary between art and life is undone. What matters is not whether it is art or not, but how experience or event changes the conditions of experience. When art becomes the way and not the end, smaller movements become guiding processes to come.

Keywords: Minor movement; Minor gesture; Art; Event; Experience.

Moringa Artes do Espetáculo, João Pessoa, UFPB, v. 10 n. 2, jun-dez/2019, p. 11 a 24

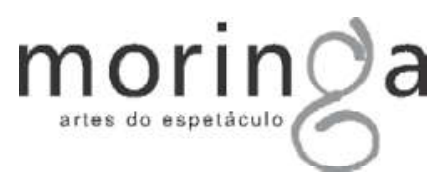




\section{Erin Manning}

\section{Uma definição}

O gesto menor: a força gestual que abre a experiência para sua potência de variação. $O$ menor realiza isso de dentro da própria experiência, ativando uma mudança de tonalidade, uma diferença de qualidade.

\section{Uma proposição}

Um tom menor está sempre entrelaçado com tons maiores 0 menor opera o maior de dentro. $\mathrm{O}$ que vale destacar é isto: nenhum deles é fixo de antemão. O maior é a tendência estrutural que organiza a si próprio de acordo com definições de valor prédeterminadas. $\mathrm{O}$ menor é a força que flui em seu interstício, que desata sua integridade estrutural, que problematiza seus padrões normativos. A inabalável crença de que o maior é o local onde os acontecimentos ocorrem, onde os acontecimentos produzem uma diferenciação, supõe aceitar interpretações tanto do que é registrado como mudança quanto dos parâmetros existentes para mensuração de seu valor.
No entanto, enquanto os gestos majoritários da macropolítica quantificam mais facilmente as mudanças ocorridas para alterar o campo, as tendências minoritárias são o que engendram as variações sutis das quais emergem as condições de toda e qualquer mudança. Ao majoritário é dado um estatuto impróprio, se considerado como o lugar em que 0 poder de transformação reside. Isso ocorre porque é mais simples identificar grandes mudanças do que catalogar as nuances de ritmo do menor. Como resultado, esses ritmos são descritos como secundários, ou até mesmo como insignificantes.

\section{Como se move?}

O menor é uma contínua variação na experiência. Possui uma mobilidade inexistente no maior: seus ritmos não são controlados por nenhuma estrutura preexistente, mas estão abertos ao fluxo. Na variação, o menor está em mudança, indeterminadamente. Mas, por ser selvagem, a indeterminação é frequentemente considerada sem rigor, frágil, sua

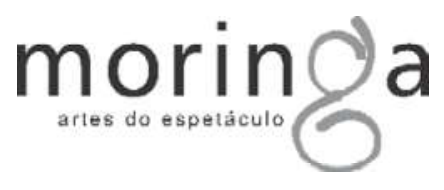


falta de solidez é tida erroneamente como inconsistente. $\mathrm{Na}$ composição das notas maiores, o menor é, então, descartado, esquecido, ignorado. Essa é a desvantagem do menor, mas também sua força: para manter sua vivacidade, ele não precisa ter a força total daquilo que guarda 0 estatuto da preexistência, de uma estrutura dada, de uma métrica pré-determinada. Ele está fora do tempo, extemporâneo, inventando ritmicamente seu próprio pulsar.

\section{O que o torna conhecido?}

O menor não é conhecido de antemão. Nunca se reproduz em sua própria imagem. Cada gesto menor está singularmente conectado com o acontecimento em questão, imanente ao in-act. $\mathrm{O}$ acontecimento é definido de acordo com o conceito de ocasião atual de Alfred North Whitehead (1978). As ocasiões atuais são o vir-a-ser da indeterminação, onde a potencialidade passa à realização. O gesto menor está ativo nessa fase de indeterminação do acontecimento. A indeterminação $\mathrm{e}$ a pontuação estão sempre em cocomposição. $O$ que o gesto menor torna perceptível é que o processo não é infinitamente aberto, mas um processo pontuado.

acontecimento e o gesto menor estão sempre em co-composição, o gesto menor move o desdobrar do acontecimento em direções novas e divergentes, que alteram a orientação de onde o acontecimento poderia de outra forma ter se fixado.

Nesse sentido, 0 gesto menor é, assim, ao mesmo tempo, pontuação e mais-que, sempre excede a formação do acontecimento. Se sua pontuação é entendida como sua parte pragmática, pode-se dizer que a qualidade do mais-que é a sua parte especulativa.

No modo do pragmatismo especulativo, o gesto menor inventa seu próprio valor, um valor tanto efêmero quanto movente. Essa permeabilidade tende a tornálo inapreensível, e, frequentemente, irreconhecível: não resta dúvida de que é difícil avaliar o que tem pouca forma perceptiva, para o que não foi

Moringa Artes do Espetáculo, João Pessoa, UFPB, v. 10 n. 2, jun-dez/2019, p. 11 a 24

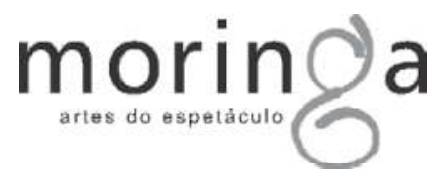




\section{Erin Manning}

inventado ainda, muito menos definido. E, assim, o gesto menor passa geralmente como algo imperceptível, seus improvisados fios de variabilidade ignorados, a despeito de estarem entremeados a tudo. $O$ menor é inquestionavelmente precário.

$\mathrm{E}$, entretanto, o gesto menor está em toda parte, todo o tempo. Malgrado sua precariedade, reemerge pontualmente, reivindicando não um espaço enquanto tal, mas um espaço-devariação. $O$ gesto menor inventa novas formas de existência, e, com elas, nelas, vimos a ser. Essas formas de vida intermitentes viajam por entre os dias, tornando obsoletas as estruturas políticas, ativando novos modos de percepção, inventando linguagens que falam no interstício de línguas maiores.

\section{Nas margens?}

O gesto menor não é a figura do marginal, embora o marginal possa carregar uma afinidade especial pelo menor e desejar se compor com ele. Gilles Deleuze escreve:
Não são os marginais que criam as linhas; eles se instalam sobre essas linhas, fazem dela sua propriedade, e é perfeito quando eles têm a curiosa modéstia dos homens de linha, a prudência do experimentador, mas é a catástrofe quando deslizam para um buraco negro, de onde não sai mais do que a palavra microfascista de sua dependência e de seu atordoamento: 'Nós somos a vanguarda', 'nós somos os marginais 1988, p. 113)

O gesto menor é a força que faz tremer as linhas que compõem os dias, as linhas estruturais e fragmentárias que articulam maneiras outras da experiência se expressar. Compor com o gesto menor requer, como Deleuze adverte, a prudência do experimentador, uma prudência atenta ao pragmatismo especulativo no seio da gênese do acontecimento. Cria técnicas de prudência experimental, uma prudência suficientemente paciente para envolver-se com aquilo que a experimentação desestabiliza, uma prudência em afinação com a força do in-act. Mas, cuidado: esta não é a prudência de um desviante passivo. É a tentativa em ato de

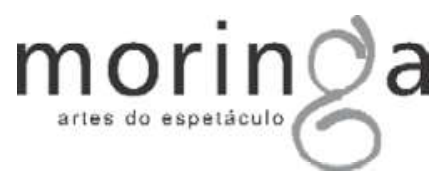


aproveitar a chance de descobrir o que mais pode um acontecimento produzir. É uma prudência que se compõe nas margens do aindanão-pensado, no ritmo do gesto menor.

\section{Como isso é um gesto?}

O menor é um gesto no sentido de que é o ativador, o portador, 0 agenciamento que desenha o acontecimento. É a força capaz de portar a tonalidade afetiva de ressonância nãoconsciente, movendo-a para a articulação, penetrando na consciência, de novos modos de existência.

\section{Uma política do menor}

Em sua reorientação pontuante do acontecimento, 0 gesto menor inventa novos modos de viver-uma-vida. Ele se move através do acontecimento, cria uma pulsação, abre caminho para novas tendências emergirem, e, nas ressonâncias que são despertadas, um potencial para diferença se aproxima.
Uma política do menor pode ser assim definida: a diferença cujo registro no acontecimento ativa um movimento que aponta para novos modos de encontro e cria novas formas de viver-uma-vida. O uso que é feito de viver-uma-vida recusa privilegiar esta vida, a humana, às custas das diferentes formas e forças da vida, mesmo quando reconhece a relevância da pontualidade deste acontecimento singular, ao qual chamamos: nossa vida. Viver-uma-vida é uma maneira de pensar a vida com e para além do humano, uma maneira de pensá-la como maisque humana. $\mathrm{O}$ conceito deleuziano de uma vida, expresso na derradeira ode à vida escrita por Deleuze (2016), ressoa fortemente aqui. Uma vida define-se pelo fluxo vital que atravessa a experiência ilimitada. A conjunção entre o gesto menor e o viver-uma-vida é uma ecologia política que opera no nível do in-act e que pergunta a cada junção o que mais a vida poderia ser. O como esta singular orientação-da-vida carrega a existência, bem como para onde o

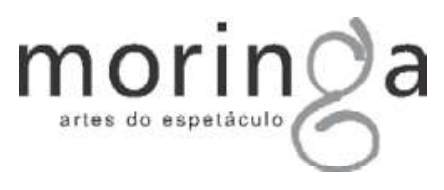




\section{Erin Manning}

gesto menor a leva são, para mim, sempre, uma questão política.

\section{E a arte?}

Proponho que trabalhemos com a definição medieval de arte como modo, jeito ou maneira. A arte como um modo ainda não trata de um objeto, de uma forma ou de um conteúdo. Está ainda por vir. Como tal, está profundamente aliada à definição de intuição de Bergson (2005), como a arte a maneira pela qual as próprias condições da experiência são sentidas. A intuição, Bergson a define, tanto estabelece um processo porvir quanto atua, na experiência, como a virada decisiva que ativa uma abertura produtiva nas dobras de duração do tempo. A intuição cria o problema operativo.

Em sua condição de sentir a potência futura, a intuição toca $o$ nervo sensível do tempo. A intuição não é tempo ou duração per se. A intuição, escreve Deleuze, é sobretudo o movimento pelo qual saímos de nossa própria duração, - movimento pelo qual nos servimos de nossa duração para afirmar e reconhecer imediatamente a existência de outras durações acima ou abaixo de nós (DELEUZE, 2008, p. 23). A intuição é o movimento relacional pelo qual o presente começa a coexistir com sua futuridade, com a qualidade ou com a maneira do não-ainda à espreita nas margens da experiência. A arte, quero propor, é isto: o potencial intuitivo que ativa do futuro no presente que escapa, que torna o entremeio da experiência perceptível ali onde futuridade e presentidade coincidem, que invoca a memória não do que foi, mas do que será. Arte, a memória do futuro.

\section{A arte do tempo}

Para Whitehead (1978), toda experiência é in-act, misturando-se de distintas maneiras com os limites do não-ainda (not-yet) e do terá sido (will have been). A experiência é/está (em) movimento.

Quando a arte é definida como objeto, como forma, nos deparamos com um paradoxo. Para que uma teoria do objeto exista, o objeto tem que ser concebido como fora do tempo, relegado para além da experiência, imutável. No entanto, na experiência, o que chamamos de

Moringa Artes do Espetáculo, João Pessoa, UFPB, v. 10 n. 2, jun-dez/2019, p. 11 a 24

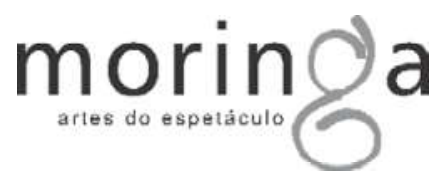


objeto é sempre, em algum grau, um não-ainda em processo, em movimento. No acontecimento, no meio, conhecemos o objeto não em sua plenitude, em sua forma última, mas como algo que nos faz penetrar na experiência.

A forma é sempre mantida, até certo ponto, em suspensão. Que o objeto não se estabeleça definitivamente de uma vez por todas na experiência, não significa que o que conhecemos como um objeto dado uma cadeira, uma pintura, uma bola está contido em algum lugar inatingível. $O$ objeto é a suspensão o sentir-da-forma (a forma sentida, não atualizada) não pode ser separado do milieu, do campo que co-ativa: no caso da cadeira, algo como uma ecologia do conforto, da sentabilidade, da inclinação para o sentar. Se essa inclinação deriva por entre as margens da sentabilidade ou se tende para a abundância do conforto, a experiência da cadeira nunca é finita, nunca é contida pelas dimensões do objeto (ou do sujeito) em si. O objeto, como o sujeito, não é nunca em si mesmo.
A arte pode fazer este maisque do objeto percebido. Isso ocorre através da capacidade da arte de trazer à expressão o tempodo-acontecimento. Esta elaboração da arte do tempo envolve a ativação da diferença do tempo. No acontecimento, a ativação da dinâmica diferenciante cria, entre o que foi e o que será, uma memória do futuro. A memória do futuro é a sensação de uma tendência que o gesto menor aciona no acontecimento. Quando a arte opera em seu máximo fulgor, tal tendência não se assenta em um objeto. Move-se através dele, empurrando o agora da experiência se fazendo ao seu limite. A maneira (manner) da arte é sentida aí, na abertura irriquieta entre $o$ agora e o agora.

\section{Artisticidade}

Raymond Ruyer (1958) fala de um rendimento estético. Qual a natureza do rendimento que a suspensão da forma propõe? Qual é a arte desse rendimento? Chamo isso de artisticidade. A artisticidade é a expressão operativa de mundos

Moringa Artes do Espetáculo, João Pessoa, UFPB, v. 10 n. 2, jun-dez/2019, p. 11 a 24

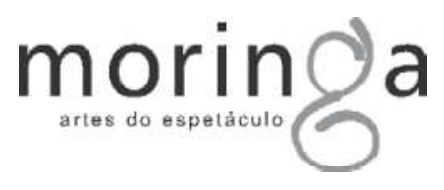




\section{Erin Manning}

se fazendo, o rendimento estético que abre a experiência à qualidade transindividual do mais-que. Artisticidade é uma direcionalidade imanente, percebida quando um processo agora na forma de um objeto continua a ativar sua dobra mais sensível, uma dobra onde a intuição é ainda abundante.

A artisticidade está para
além do humano. A arte como
modo, como maneira, como jeito,
não é propriedade do humano.
Certamente, corta através do
humano, funde-se com ele,
captura-o, dança com ele, mas é
também e sempre mais-que
humana. Tocar a artisticidade
significa tocar o mais-que
incomensurável que está ativo nas
ecologias que nos produzem e nos
excedem.

\section{Coletividade emergente}

A arte se torna, no seu processo de feitura e uma vez torcida em direção à artisticidade, um caminho para um ethos de transindividuação. Da estrutura mais aparentemente estável ao processo mais móvel e efêmero, a arte que é artisticiosa (art that is artful) ativa a arte da participação, fazendo sentir a força transindividual de um tempo acontecimental que catapulta o humano em nossa diferença. Essa diferença, o mais-que em nosso âmago, a parte não-humana que anima cada uma de nossas células, passa a estar atenta ao campo relacional que abre a obra para o seu fora intensivo. Esse campo relacional não deve ser entendido espacialmente. Ele é uma matéria intensiva, uma movência absoluta que habita de maneira duracional a obra. É a arte do tempo fazendo-se sensível.

Quando um campo da diferença é ativado, isso requer cuidado. A arte participativa envolve criar as condições para que esse cuidado tenha lugar. $\mathrm{O}$ cuidado é, primeiro e principalmente, um cuidado com o ambiente frágil da duração gerado pela operatividade da obra e ativado pelo gesto menor. Um cuidado pelos ritmos nascentes da obra.

\section{Além do valor?}

A artisticidade não tem valor-de-uso não produz nada que possa ser mapeado por um

Moringa Artes do Espetáculo, João Pessoa, UFPB, v. 10 n. 2, jun-dez/2019, p. 11 a 24

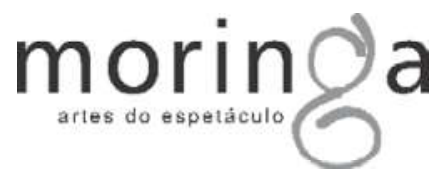


processo já em curso. Não há finalidade, não há limites preordenados, nenhum código moral. Mas a artisticidade é condicionante. Tal afirmação estabelece que as restrições permissivas de sua emergência facilitam um engajamento oportuno com o problema vigente, permitindo a passagem para um campo de rendimento. A prática realiza o seu trabalho quando o gesto menor torna operativo esse rendimento já presente em germe no problema inicial que ativa o processo, na intuição que o orienta. $O$ estético não rende sem as condições propícias.

$$
\text { Condições propícias }
$$
facilitam a contemplação. A contemplação, entendida como o ato de persistir-com, de cuidado com um processo, é uma forma mínima de produção. Toma parte nas condições que fazem uma obra desdobrar-se. A contemplação é passiva somente no sentido de que essa participação provoca uma espera, uma paragem, uma escuta, uma simpatia-com. Essa simpatia está envelopada no processo, simpática com a parte indizível da experiência atiçada pelo gesto menor, em afinação com a frágil arte do tempo. Operativa nas margens da percepção, ali onde consciência e não-consciência se sobrepõem, a contemplação ativa temporalidades de seu próprio fazer. Por isso, a contemplação, assim como a intuição, ativa a diferenciação de um acontecimento, e, em sendo assim, torna-se suscetível às nuances sutis da experiência se construindo.

A contemplação torna perceptível o artisticioso (artful). Isso ocorre no acontecimento, na oscilação inquieta entre semear uma prática e devir-com a prática. Aqui, no meio do viver-uma-vida, a artisticidade nos lembra que a vida não começa com o eu, e o tu não é o que a transforma em arte. Constituída de milhares de contemplações, a arte do tempo nos relembra que não dizemos eu a não ser por estas mil testemunhas que contemplam em nós; é sempre um terceiro que diz eu (DELEUZE, 2018, p. 80). É por isso que artisticidade é mais rara que a arte.

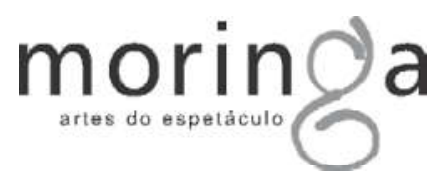




\section{Erin Manning}

Artisticidade: o modo como a arte do tempo se faz sensível, como aterrissa, e como sempre excede sua aterrissagem.

\section{Um diagrama para viver a} vida?

Diagramas alternativos para viver-uma-vida devem resistir ao retorno de um modelo de interiorexterior, no qual o sujeito humano está situado como o motor da experiência. Este é o nosso hábito: fazer da obra algo sobre nós mesmos. Em sendo assim, as condições estabelecidas somente são generativas se referentes ao que percebemos como nosso próprio bem-estar. Delimitar a abordagem do político dessa maneira, faz com que o sujeito, o humano, fique na posição de agente, promovendo o agir nos termos do impulso volitivo de nossa intencionalidade. Mesmo se damos voz aos silenciados, se discursamos em nome da multidão, se mencionamos a agência de um processo artístico, se concebemos agência aos povos oprimidos, há a pressuposição da mediação entre o ato e seu desdobramento. E se o ato não nos pertencesse plenamente?

\section{Quando o movimento nos excede}

Não criamos gestos menores porque eles não são nossos. O menor é percebido por aquilo que produz no campo de experiência. No campo das artes, a obra, o objeto, ou mesmo o efeito criado por uma composição efêmera, não são, em si, gestos menores. $\mathrm{O}$ gesto menor é o que ativa, em condições precisas, a obra, é o que torna as afinações de uma ecologia emergente perceptíveis, é o que faz a obra obrar-se.

O movimento do gesto menor é da ordem da decisão antes de ser da volição. Define-se a decisão aqui não como algo exterior à experiência, mas como um corte dentro do acontecimento, pelo qual novas ecologias e novos campos relacionais são criados. $O$ movimento não-consciente é decisional por ser capaz de alterar - curso do acontecimento no acontecimento. Em outro lugar, dei - nome de pensamento coreográfico a essa afinação que

Moringa Artes do Espetáculo, João Pessoa, UFPB, v. 10 n. 2, jun-dez/2019, p. 11 a 24

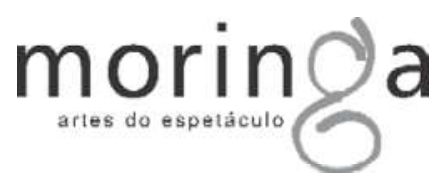


ocorre no acontecimento relativa ao movimento decisional, sublinhando a aptidão do movimento de incitar e alinhar espaços-tempos composicionais de forma a abrir a experiência para novos registros. A decisão não é o que ocorre após a abertura afetiva do acontecimento para a sua potencialidade, mas 0 que fende $\mathrm{o}$ acontecimento no acontecimento. O gesto menor é um corte decisional.

\section{Uma liberdade menor?}

Os gestos menores reformulam o campo, fazendo com que seu diferencial seja perceptível. Realizam isso quando ativam, no acontecimento, uma mudança de direção, uma mudança de qualidade. A ativação de uma mudança de qualidade é o que Bergson chama de liberdade. A liberdade não está ligada com a volição ou agência humana. Em vez disso, a liberdade alia-se com o in-act, com a força decisória da movência, com o agenciamento que fende $o$ acontecimento para a totalidade do seu potencial. A liberdade é o modo como o acontecimento expressa sua liberdade em seu próprio acontecer.

A liberdade, para Bergson (2001), é dinâmica, ecológica. A liberdade é uma qualidade do ato, um ethos na abertura do ato à experiência. Os acontecimentos não são todos livres, mas, em todo acontecimento, encontramos os germes da liberdade. Esses germes devem ser cuidados, cultivados, de tal forma que propiciem ao ato a invenção de problemas que irão gerar modos de ação, de atividade, de ativismo que criam novos modos de existência. Os gestos menores cuidam dos germes da experiência informação, abrindo o agir para o seu potencial. Nesse aspecto, o gesto menor é uma força de liberdade. Por isso, o gesto é um gesto menor na exata medida em que abre os caminhos, em que cria as condições para uma diferente ecologia do tempo, do espaço, da política. O gesto menor, vale frisar, é definido pela sua capacidade de variar, não de conservar, de conter. Suas gestualidades agem e se movimentam tendo em vista

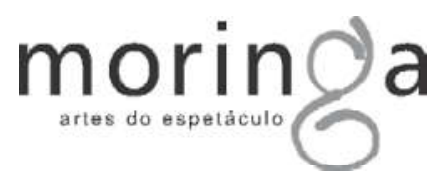




\section{Erin Manning}

sempre a futuridade presente em ato, mesmo que ainda inexprimíveis. Esta é a força do gesto menor, seu grito por liberdade.

A liberdade talvez não seja uma palavra a se agarrar, dado o peso de sua história e seu mal uso constante. Por ora, utilizo-a apenas como um marcador para nos relembrar que a volição e a liberdade não precisam ser pensadas como complementares. Não precisamos estar no centro de nossa liberdade. Como Bergson escreve: o processo da nossa atividade livre prossegue, de algum modo, sem nós sabermos, em todos os momentos da duração, nas obscuras profundidades da nossa consciência, que o próprio sentimento da duração precede daí (BERGSON, 2001, p. 163). A heterogeneidade da descontínua natureza da experiência é, seguramente, difícil de articular, mas é infinitamente rico. Para escutá-la, é necessário abster-se de definir a experiência separada do in-act.
16. Aqui, agora.

Nos interstícios do que foi composto e do que está prestes a se compor, há muito ainda a ser dito, desenhado. Aqui, agora, nesta exploração transversal do que um gesto menor pode fazer, emerge a pergunta de como poderíamos dar conta da entrada do movimento menor no mundo. Algumas ideias:

- Movimentos menores são menos da ordem da criação do que da afinação.

- Para a ativação de movimentos menores, um processo curatorial requer uma afinação com as condições que selecionam a artisticidade.

- Afinar-se com a artisticidade abre a obra para o seu mais-que.

- O mais-que é o que é escolhido (curado).

- Ativado um meio ambiente, emerge um avivamento de uma ecologia.

- Com o avivamento, a experiência da dobra do tempo é sentida.

- A dobra do tempo move a experiência para 0 seu desdobramento emergente. 


\begin{tabular}{llr} 
- Nesse & \multicolumn{2}{r}{ desdobramento } \\
emergente, & não & somos \\
espectadores. & &
\end{tabular}

- Os desdobramentos emergentes afetam o meio ambiente que eles co-compõem.

- Somos parte dessa cocomposição.

- Compor um movimento menor é ser composto por ele.

- Um processo curatorial para a ativação de movimentos menores requer uma transformação ativa do pressuposto de que existe um campo da arte e um campo da vida.

- O político percorre o diferencial que é composto quando o binarismo entre arte e vida é desfeito.

- O que importa não é se é ou não arte, mas como muda as condições da experiência.

- Quando a arte se torna o caminho e não o fim, os movimentos menores se tornam orientadores dos processos por vir.

Recebido em: 01/08/2019

Aceito em: 25/08/2019

\section{Referências Bibliográficas}

BERGSON, Henri. Creative Evolution. Translated by Arthur Mitchell. New York: Dover, 1998. (Edição brasileira: A evolução criadora. Trad. Bento Prado Neto. São Paulo: Martins Fontes, 2005).

BERGSON, Henri. Time and Free Will: an Essay on the Immediate Data of Consciousness. Translated by F. L. Pogson. New York: Dover, 2001.

DELEUZE, Gilles. Parnet, Claire. Dialogues. New York: Columbia University Press, 2007. (Edição brasileira: DELEUZE, Gilles; PARNET, Claire. Diálogos. Trad. Eloísa Araújo Ribeiro. São Paulo: Escuta, 1988).

DELEUZE, Gilles. 1991. Bergsonism. Translated by Hugh Tomlinson and Barbara Habberjam. New York: Zone Books. (Edição brasileira: 0 bergsonismo. Trad. Luiz B. L. Orlandi. São Paulo: Editora 34, 2008).

DELEUZE, Gilles. Pure Immanence: Essays on a Life. New York: Zone Books, 2005. (Edição brasileira: Imanência: uma vida. In: Dois regimes de loucos. Org: David Lapoujade. Trad.

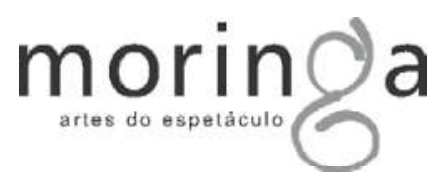




\section{Erin Manning}

Guilherme Ivo. São Paulo: Editora 34, 2016).

DELEUZE, Gilles. Difference and Repetition. Translated by Paul Patton. New York: Columbia University Press, 1978. (Edição brasileira: Diferença e repetição. Trad. Luiz B. L. Orlandi e Roberto
Machado. São Paulo: Paz e Terra, 2018).

RUYER, Raymond. La genèse des formes vivantes. Paris: Flammarion, 1958.

WHITEHEAD, Alfred North. Process and Reality. New York: Free Press, 1978. 